\title{
THE EFFECT OF DIFFERENT IRRIGATION PERIODS ON GROWTH INDICATORS OF SOME WEED SPECIES
}

\author{
ASADI, S. ${ }^{*}$-ABADI, H. R. M. D. C. - ASGARI, A. - ZADEH, P. S. \\ Faculty of Agriculture, University of Mohaghegh Ardabili, Ardabil, Iran \\ *Corresponding author \\ e-mail:behtari@live.com \\ (Received 25 $5^{\text {th }}$ Mar 2019; accepted $12^{\text {th }}$ Jul 2019)
}

\begin{abstract}
Environmental conditions have a great influence on the growth and development of weeds and, consequently, on their ability to compete, and changing these conditions can be effective in weed management. For this purpose, an experiment was carried out in 2016 and 2017 in the greenhouse of the Faculty of Agriculture and Natural Resources, University of Mohaghegh Ardabili, Iran. The studied factors were four weed species Red root pigweed (Amaranthus retroflexus), Jimsonweed (Datura stramonium), Russian knapweed (Acroptilon repens $\mathrm{L}$ ) and Catchweed (Setaria verticilata) and three irrigation periods to field capacity (irrigation daily (control), irrigation once in every three days and irrigated once every six days). Results showed that with increasing irrigation period, Leaf Area Index (LAI), Relative Growth Rate (RGR), Weed Growth Rate (WGR), Net Assimilation Rate (NAR) and Total Dry Matter (TDM) decreased. The extent of decrease in growth indices was different between weeds $\mathrm{C} 3$ and $\mathrm{C} 4$. Total dry matter of Catchweed and Red root pigweed responded to increased irrigation periods less than others. In control irrigation, Jimsonweed growth indices were higher than other weeds, but to exert stress and increasing irrigation periods, Red root pigweed was more successful and a stronger competitor.

Keywords: weeds management, environmental conditions, growth analysis, drought stress, irrigation period
\end{abstract}

\section{Introduction}

Weeds are a hidden foe for crop plants, interfering with their functions and suppressing their growth and development. Hence, weeds have been documented as serious plant pests since the ancient times. Environmental factors influence weed growth and composition of arable weed species, therefore need more accurate estimations of the damage potential of arable weeds to develop effective weed control strategies while maintaining crop yield (Zimdahl, 2013; Peters et al., 2014). The purpose of the study of physiological characteristics is to describe or explain how the plant reacts to environmental conditions (Beech and Norman, 2002). One of the major problems in the production of agricultural products is the competition of weeds over growth resources, especially water stored in the soil (Monaco et al., 2002). In addition to weeds competition, drought stress is another factor in reducing production. Drought is one of the most important environmental stresses that has destructive and harmful effects on different plant growth stages, organ structure and activity (Eslami et al., 2012). In different experiments, humidity and temperature are mentioned as the most influential environmental factors on the growth of weed seedlings (Benvenuti et al., 2001). Results of Chauhan and Johnson (2010) showed that with increasing drought stress, the vegetative and reproductive characteristics of barnyard grass weed (Echinochola cruss- galli L.) decreased. Webster and Grey (2008) reported that under drought stress the biomass of Commelina benghalensis decreased. In research studies on the effect of irrigation periods $(1,3,6,9,12$ and 15 days) on weed growth characteristics of Echinochloa colona and Rottboellia cochinchinensis, it was found that 
in general, with prolonging irrigation periods, height, number of leaves, number of stems, dry weight of shoot, root dry weight and seed production of these weeds decreased (Chauhan and Johnson, 2010 and Chauhan, 2013). Since changes in weeds growth indices have been considered less than environmental conditions change, so this experiment was conducted to evaluate the effect of irrigation periods on growth indices of Red root pigweed (Amaranthus retroflexus), Jimsonweed (Datura stramonium), Russian knapweed (Acroptilon repens $L$ ) and Catchweed (Setaria verticilata).

\section{Materials and methods}

The experiment was carried out as a factorial experiment based on randomized complete block design with five replications in the greenhouse of the Faculty of Agriculture and Natural Resources, University of Mohaghegh Ardebili, Iran during 2016 and 2017. The studied factors were four weed species; Red root pigweed (Amaranthus retroflexus), Jimsonweed (Datura stramonium), Russian knapweed (Acroptilon repens $L$ ) and Catchweed (Setaria verticilata) and three irrigation periods to field capacity (irrigation daily (control), irrigation once in every three days and irrigated once every six days). Weed seeds were collected from the surrounding farms. For planting nylon $12 \mathrm{~L}$ pots $(26 \times 36 \mathrm{~cm})$ were filled with agricultural soil until sufficient growth conditions were provided for the roots. The amount of soil within each pot was $10 \mathrm{~kg}$. The soil characteristics are shown in Table 1. Weed seeds were planted at a depth of $1 \mathrm{~cm}$ and immediately irrigated to field capacity. Roots of the same Russian knapweed were cultivated horizontally at a depth of $4 \mathrm{~cm}$. Four pots were considered for each treatment in each replication, in order to destructive sampling. After germination of seeds, different irrigation periods were performed. Sampling started from the four-leaf stage of the plants and repeated once every 10 days. For this purpose, the plants were cut from soil surface, and after measuring the leaf area and their number, they were dried in an oven for $48 \mathrm{~h}$ at $75{ }^{\circ} \mathrm{C}$. The roots were also separated from the soil by washing and their weight and length were measured. The length of the root was measured by measuring the longest root length with a ruler. Also, in measuring root dry weight, the root system of the plant was washed after being placed in an oven with a numerical scale of 0.001 . To exit healthy roots, the soil is poured into nylon pots, at the end of the work, the pots were placed in the water pond and the root soil was washed out. For the above characteristics, analysis of variance and comparison of mean of cultivars were performed using SAS software.

Table 1. Soil physical and chemistry properties

\begin{tabular}{c|c|c|c|c|c|c}
\hline $\mathbf{p H}$ & $\mathbf{E C}(\mathbf{M s} / \mathbf{c m})$ & OM \% & Soil texture & Clay & Silt & Sand \\
\hline 7.8 & 366 & 1.74 & Clay loam & 36.72 & 34.56 & 28.72 \\
\hline
\end{tabular}

Growth analysis parameters such as Total Dry Matter (TDM), Relative Growth Rate (RGR), Weed Growth Rate (WGR), Leaf Area Index (LAI), and Net Assimilation Rate (NAR) were measured using the following relationships (Rosal et al., 1984), and the charts were drawn with the help of Excel software.

$$
\mathrm{TDM}=\mathrm{e}^{(\mathrm{a} 1+\mathrm{b} 1 \mathrm{t}+\mathrm{c} 1 \mathrm{t} 2+\mathrm{d} 1 \mathrm{t} 3)}
$$


where TDM, total dry matter $\left(\mathrm{g} / \mathrm{m}^{2}\right)$, was obtained by weighing the total dry matter of the plant in square meter.

$$
\mathrm{LAI}=\mathrm{e}^{(\mathrm{a} 2+\mathrm{b} 2 \mathrm{t}+\mathrm{c} 2 \mathrm{t} 2+\mathrm{d} 2 \mathrm{t} 3)}
$$

where LAI: leaf area index, by measuring the leaf area with the help of the device leaf area meter, and was calculated using the formula LAI $=\mathrm{LA} / \mathrm{P}$.

$$
\mathrm{LDW}=\mathrm{e}^{(\mathrm{a} 3+\mathrm{b} 3 \mathrm{t}+\mathrm{c} 3 \mathrm{t} 2+\mathrm{d} 3 \mathrm{t} 3)}
$$

where LDW: Green leaf dry weight (g or $\mathrm{mg}$ ). Weight of green leaves dried in the oven, also, whose surface was calculated, weighed and noted. The other growth indices were calculated with the help of the following values.

$$
\mathrm{WGR}=\mathrm{RGR} \times \mathrm{TDM}
$$

where WGR: Weed growth rate $\left(\mathrm{g} \mathrm{m}^{-2} \mathrm{~d}^{-1}\right)$.

Weed growth rate is the derivative function of the total dry matter in unit of time (t) or multiplication RGR in TDM.

$$
\begin{gathered}
\mathrm{WGR}=\left(\mathrm{b} 1+2 \mathrm{c}_{1} \mathrm{t}+3 \mathrm{~d}_{1} \mathrm{t}^{2}\right) \mathrm{e}^{(\mathrm{a} 1+\mathrm{b} 1 \mathrm{t}+\mathrm{c} 1 \mathrm{t} 2+\mathrm{d} 1 \mathrm{t} 3)} \\
\mathrm{RGR}=\mathrm{TDM} / \mathrm{CGR}
\end{gathered}
$$

where RGR: Relative growth rate $\left(\mathrm{gg}^{-1} \mathrm{~d}^{-1}\right)$. Relative growth rate is the derivative of natural logarithm function of total dry matter in unit of time (t) or the result is the division of TDM on CGR.

$$
\begin{gathered}
\mathrm{Ln} T \mathrm{TDM}=\mathrm{a} 1+\mathrm{b} 1 \mathrm{t}+\mathrm{c} 1 \mathrm{t} 2+\mathrm{d} 1 \mathrm{t} 3 \\
\mathrm{RGR}=\mathrm{b} 1+2 \mathrm{c} 1 \mathrm{t}+\mathrm{d} 1 / 2 \mathrm{t} 3 \\
\mathrm{NAR}=\mathrm{CGR} / \mathrm{LAI}
\end{gathered}
$$

where NAR: net assimilation rate $\left(\mathrm{gm}^{-2} \mathrm{~d}^{-1}\right)$.

$$
\mathrm{NAR}=(\mathrm{b} 1+2 \mathrm{c} 1+3 \mathrm{~d} 1 \mathrm{t} 2) \mathrm{e}^{(\mathrm{a} 1-\mathrm{a} 2)+(\mathrm{b} 1-\mathrm{b} 2) \mathrm{t}+(\mathrm{c} 1-\mathrm{c} 2) \mathrm{t} 2+(\mathrm{d} 1-\mathrm{d} 2) \mathrm{t} 3}
$$

\section{Results and discussion}

\section{Weeds growth rate (WGR)}

The results showed that WGR was affected by irrigation periods and for all weed species was at its peak for the first irrigation periods (control) in both 2016 and 2017 years in Jimsonweed 7.5 and 8.5 g. $\mathrm{m}^{2}$ d, red root pigweed 5.5 and 6.2 g.m ${ }^{2}$. d, Russian knapweed 4 and 4.3 g.m ${ }^{2}$. d and Catchweed 3.3 and 2.9 g.m2. d. Regarding the logical and direct relationship between LAI and WGR, these results were consistent with the results obtained for LAI and showed that drought stress affects leaves development, dry matter production and growth rate. The changes trend in the growth rate of weeds in all treatments was relatively similar (Fig. 1). In control irrigation, WGR collapsed after reaching its peak at (45 to 54) days after planting the examined species. But for the second irrigation period the start of WGR collapse happens on 32-40 days, and for the 
third irrigation period on 30 to 32 days. It seems that weeds, under severe water shortages, take action by falling leaves to reduce evapotranspiration, before reaching their maximum growth, and thus lose their Carbohydrate factory. As can be viewed, WGR decreases in the third irrigation period earlier than another period. Investigating Figure 1 shows that there is a difference between the four weed species in terms of WGR. In the irrigation control, Jimsonweed has a maximum growth rate. The reason for this can be pointed out the high level of leaf area index, which that caused the sunlight more and better to use. Jimsonweed retains its leaf area, it showed more ability to reach maximum WGR, because it makes more carbohydrates and receives better radiation. Whatever growth rate of the weed has, its ability is increased to compete with the crop. Because in this case, weed can more effectively overcome the canopy of the crop and maximize the use of limited resources available (Sadeghi et al., 2009). By increasing the irrigation period, the amount of CGR in weeds decreased. Nevertheless, the extent of this reduction is accompanied by some changes. As can be seen in Figure 1, by applying stress and increasing the irrigation period, the decrease in the growth rate of Jimsonweed and Russian knapweed weeds is greater than that is of Red root pigweed and Catchweed. In fact, it is quickly impacted by stress. This can be attributed to the fact that the two weeds are C3 plants. In fact, under conditions of water shortage and drought stress, C3 weeds have less competitive power than C4 weed (Sadeghi et al., 2009). From among the two weeds of the C4, Red root pigweed has a high resistance to stress. With regard to the direct relationship between WGR and LAI, it can be concluded that red root pigweed with a high leaf area can reach to a high WGR, because it makes more carbohydrates with the receipt of better radiation (Karim Zadeh Asl et al., 2004).

Therefore, it can be concluded that Jimsonweed can be problematic in the field under stressless conditions and continuous irrigation or regular rainfall, but if rainfall reduces or irrigation is low, the weeds flora will be changed and red root pigweed will be problematic. Also, it was found out that the weed growth rate is important at the time of applying a weed management strategy, including the use of herbicides.

$$
\begin{gathered}
\mathrm{WGR}=(\mathrm{b} 1+2 \mathrm{c} 1 \mathrm{t}+3 \mathrm{~d} 1 \mathrm{t} 2) \mathrm{e}(\mathrm{a} 1+\mathrm{b} 1 \mathrm{t}+\mathrm{c} 1 \mathrm{t} 2+\mathrm{d} 1 \mathrm{t} 3) \\
\text { WGR }=\mathrm{RGR} \times \mathrm{TDM}
\end{gathered}
$$

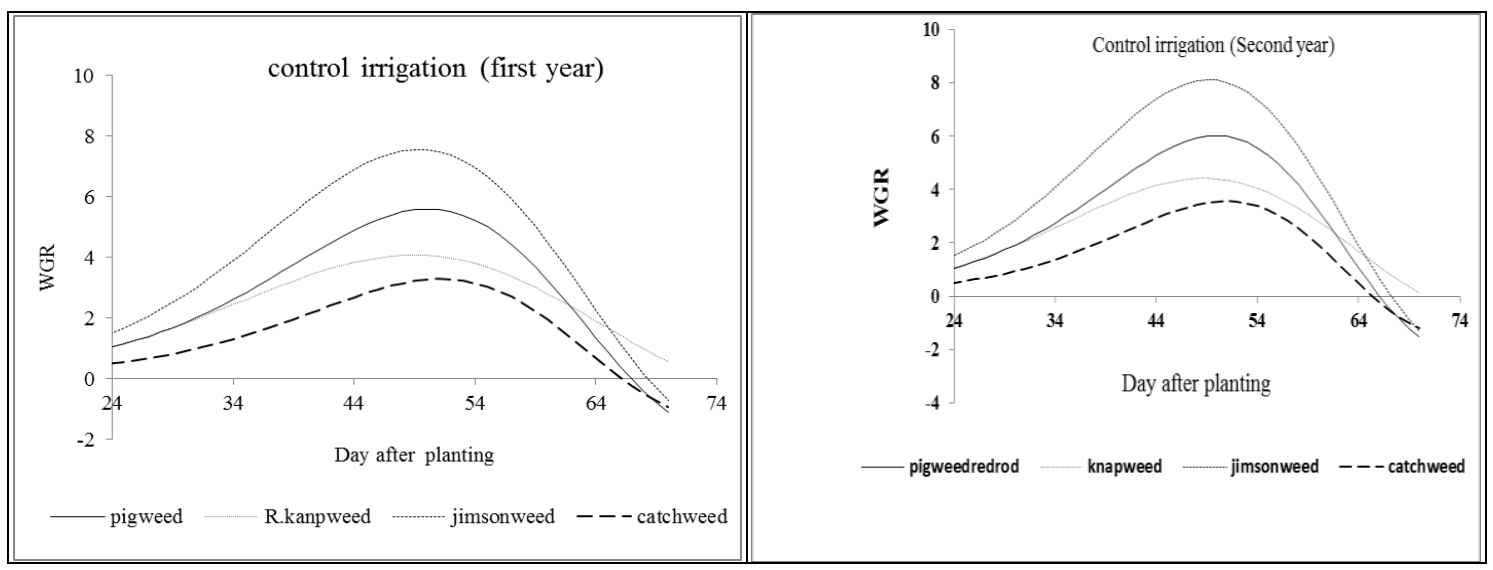




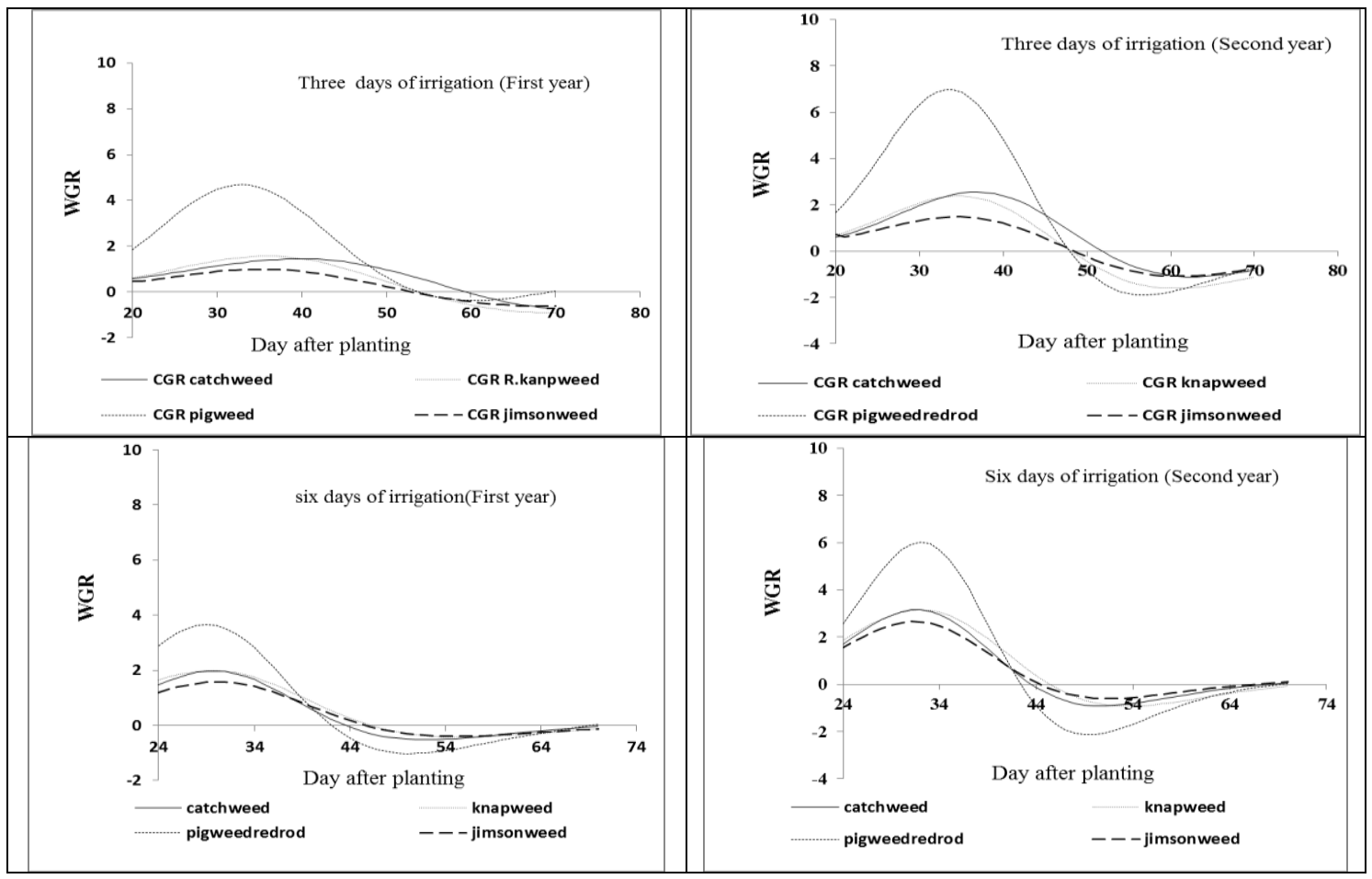

Figure 1. The effect of irrigation period on the changes trend in weed growth rate during the growing season

\section{Total dry matter (TDM)}

The results showed that in two years of experimentation, weed total dry matter declined with increasing irrigation period (Fig. 2). In all of the sampling, in the two years, Jimsonweed had the highest total dry matter (100 and $110 \mathrm{~g}$ per plant) in irrigation control. With increasing irrigation period (3 and 6 days) and applying drought stress and water shortage conditions, decreasing of Jimsonweed total dry matter was more intense. Catchweed and Red root pigweed total dry matter, changed less afoul and declined under stress conditions. This can be attributed to the fact that the two weeds are C4 plants. In fact, C3 weeds have less competitive power than weed C4 under conditions of water shortage and drought stress.

$$
\mathrm{TDM}=\mathrm{e}^{(\mathrm{a} 1+\mathrm{b} 1 \mathrm{t}+\mathrm{c} 1 \mathrm{t} 2+\mathrm{d} 1 \mathrm{t} 3)}
$$

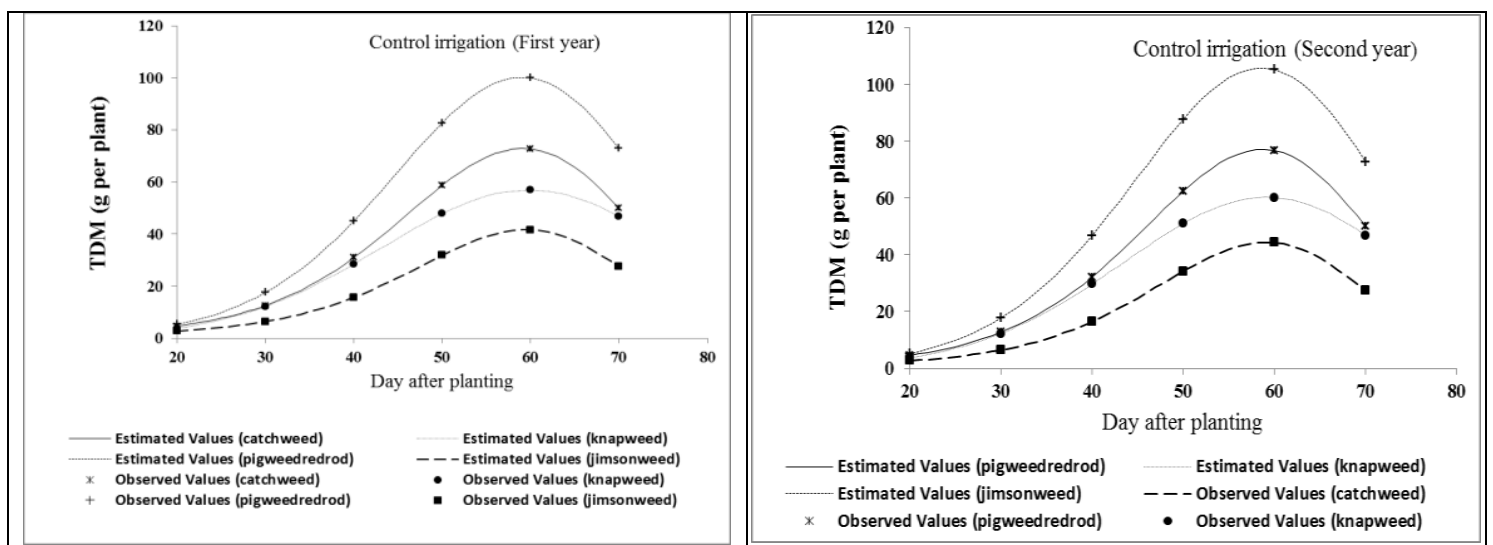




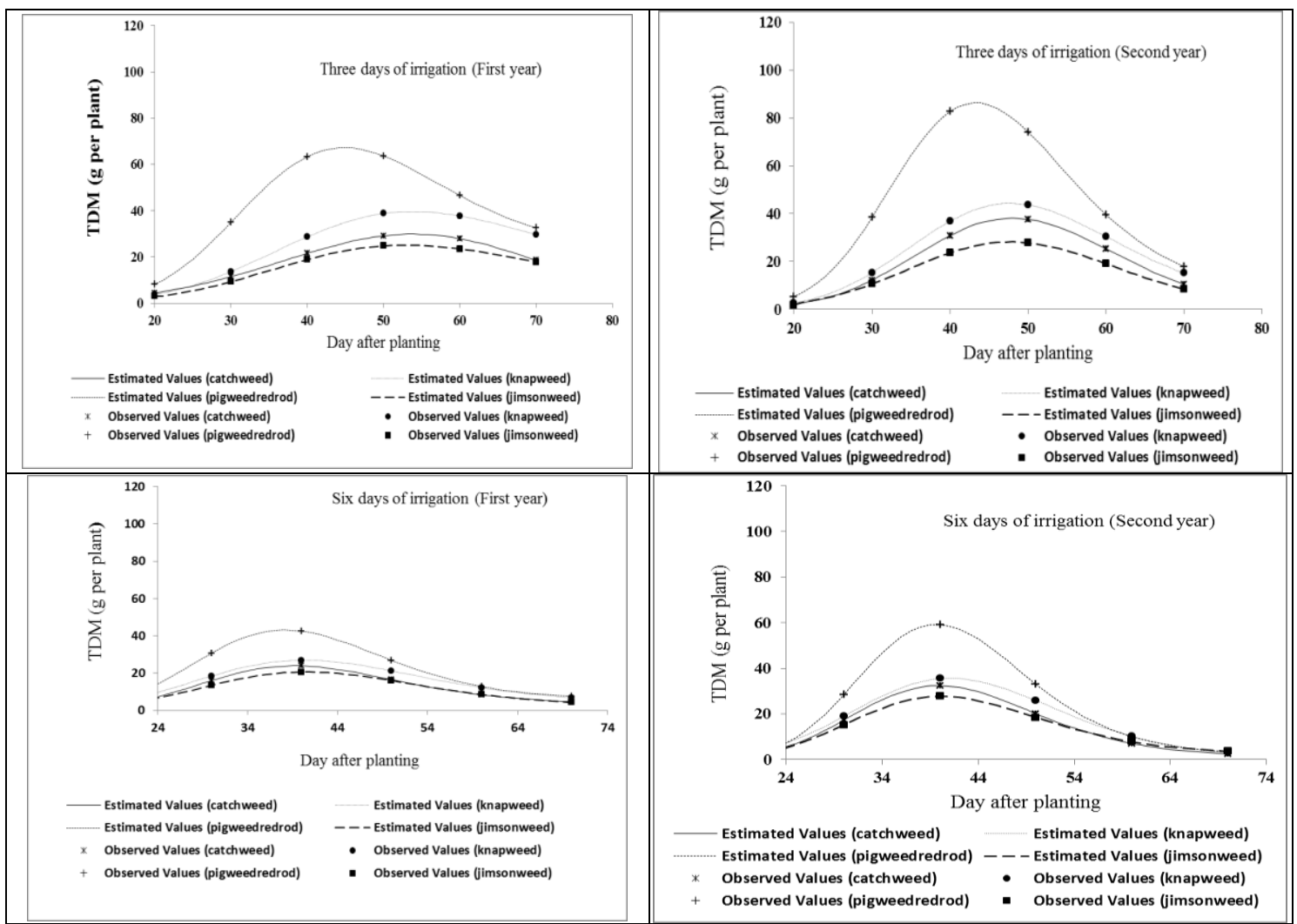

Figure 2. The effect of irrigation period on changes trend in weed total dry matter during the growing season

\section{Leaf area index (LAI)}

In the irrigation control, LAI is at its peak at all weeds examined. Jimsonweed (6 and 6.5), Red root pigweed (4.5 and 5), Russian knapweed (5.5 and 7.5) and Catchweed (2.3 and 2.7). In the meantime, LAI Jimsonweed is higher than other weeds. As seen in Figure 3, with the onset of stress and applying irrigation periods of 3 and 6 days, LAI reduced all weeds, and in 3 days, in both years, in Red root pigweed, Jimsonweed, Catchweed and Russian knapweed, it reached (3.8 and 5, 1.7 and 2, 1.5 and 2, 1.4 and 1.6) and in 6 days (2.4 and 3.2, 1.4 and 1.9, 1.9 and 2.5, 1.5 and 1.7) respectively. It is clearly that water shortage influence on plant morphology for example loss leaf number and leaf area reduction. Therefore, the results can be justified. Although the LAI begins to collapse after its peak, but it is becoming more intense with increasing irrigation periods.

Rawson and Turner (1982) concluded during the experiment that the number of leaves in sunflowers under drought stress was less than in non-stressed cultivars, also, the leaf area increased with increasing number of irrigation period. The main symptom of drought stress at the stage of growth is the reduction of the number and size of leaves. If the water shortage continues, the lower leaves fell and plant height will be significantly lower than normal.

$$
\mathrm{LAI}=\mathrm{e}(\mathrm{a} 2+\mathrm{b} 2 \mathrm{t}+\mathrm{c} 2 \mathrm{t} 2+\mathrm{d} 2 \mathrm{t} 3)
$$




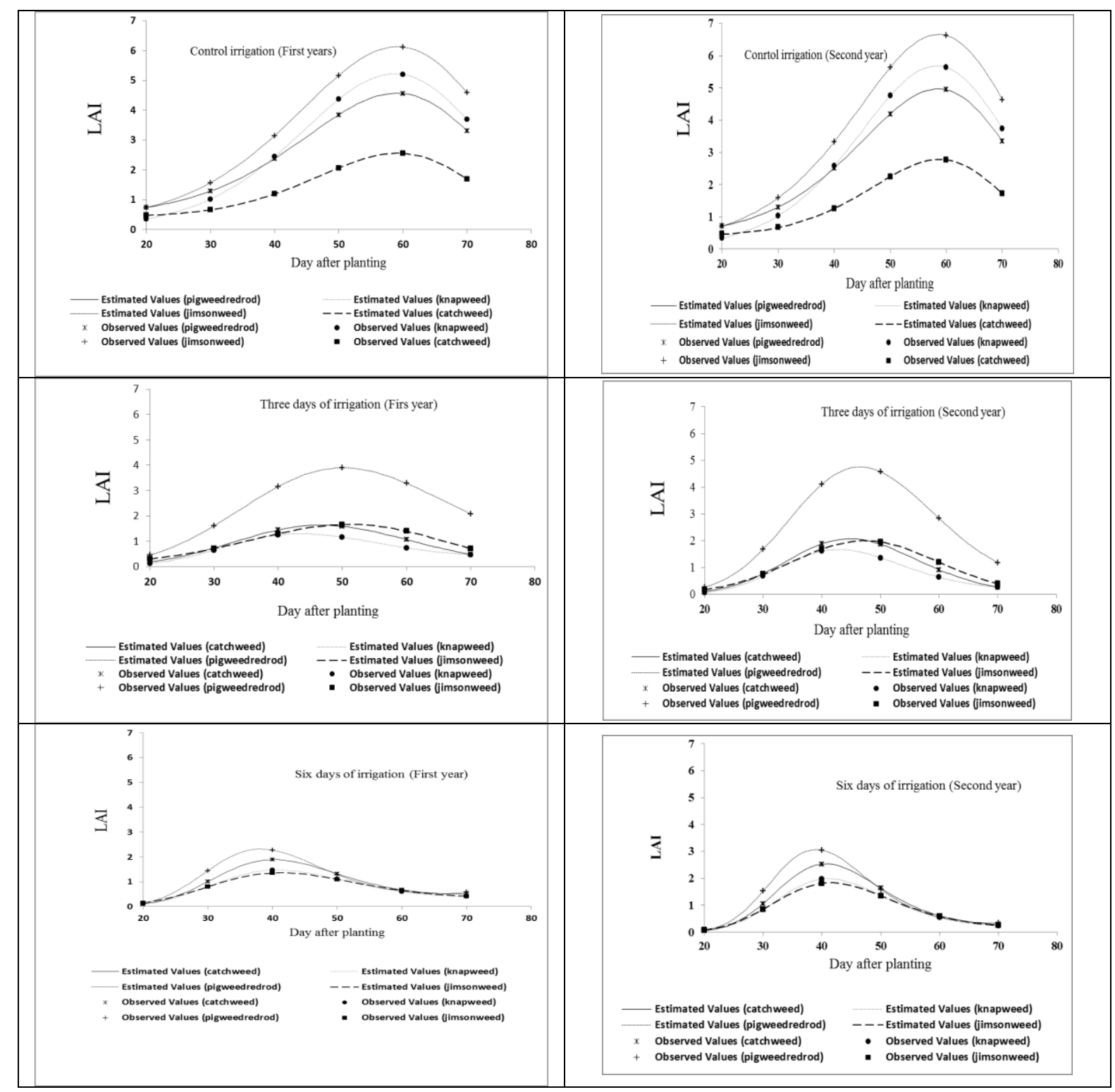

Figure 3. The effect of irrigation period on changes trend in leaf area index during the growing season

Figure 3 shows that Jimsonweed leaf area index is at a higher point than other weeds, but by applying irrigation periods, LAI reduction in Jimsonweed is more intense and it arrived less than the Red root pigweed leaf area index. Regarding what is seen from this curve in an environment without stress, Jimsonweed has better leaf area development and more potential for dry matter production than other weeds. Better leaf development allows the carbohydrate factory to be more productive and more competitive than other weeds. But by applying irrigation periods and increasing irrigation periods, it gives its place to the Red root pigweed.

\section{Relative growth rate (RGR)}

The results showed that in all irrigation periods, RGR was decreasing trend and with increasing irrigation periods, the rate of reduction of RGR also increased. RGR in all 
weeds in the first irrigation periods at 68-73 days after planting, for the second and third irrigation periods at 50-60 and 41-44 days after planting, respectively, was zero. Six days irrigation gets zero faster than three days and control treatment (Fig. 4). Human et al. (1990) stated that RGR changes have decreased mode relative time, but its slope depends on environmental factors. Drought stress causes premature aging of the plant and this mechanism for that is the plant as soon as complete its growth period to escape dryness (Kochaki and Sarmadnia, 1990). Yegappan et al. (1982) has also achieved similar results. It seems with longing irrigation periods, the RGR faster reaches to zero.

$$
\begin{gathered}
\text { RGR }=\text { TDM/CGR } \\
\operatorname{Ln} \text { TDM }=\mathrm{a} 1+\mathrm{b} 1 \mathrm{t}+\mathrm{c} 1 \mathrm{t} 2+\mathrm{d} 1 \mathrm{t} 3 \\
\mathrm{RGR}=\mathrm{b} 1+2 \mathrm{c} 1 \mathrm{t}+\mathrm{d} 1 / 2 \mathrm{t} 3
\end{gathered}
$$

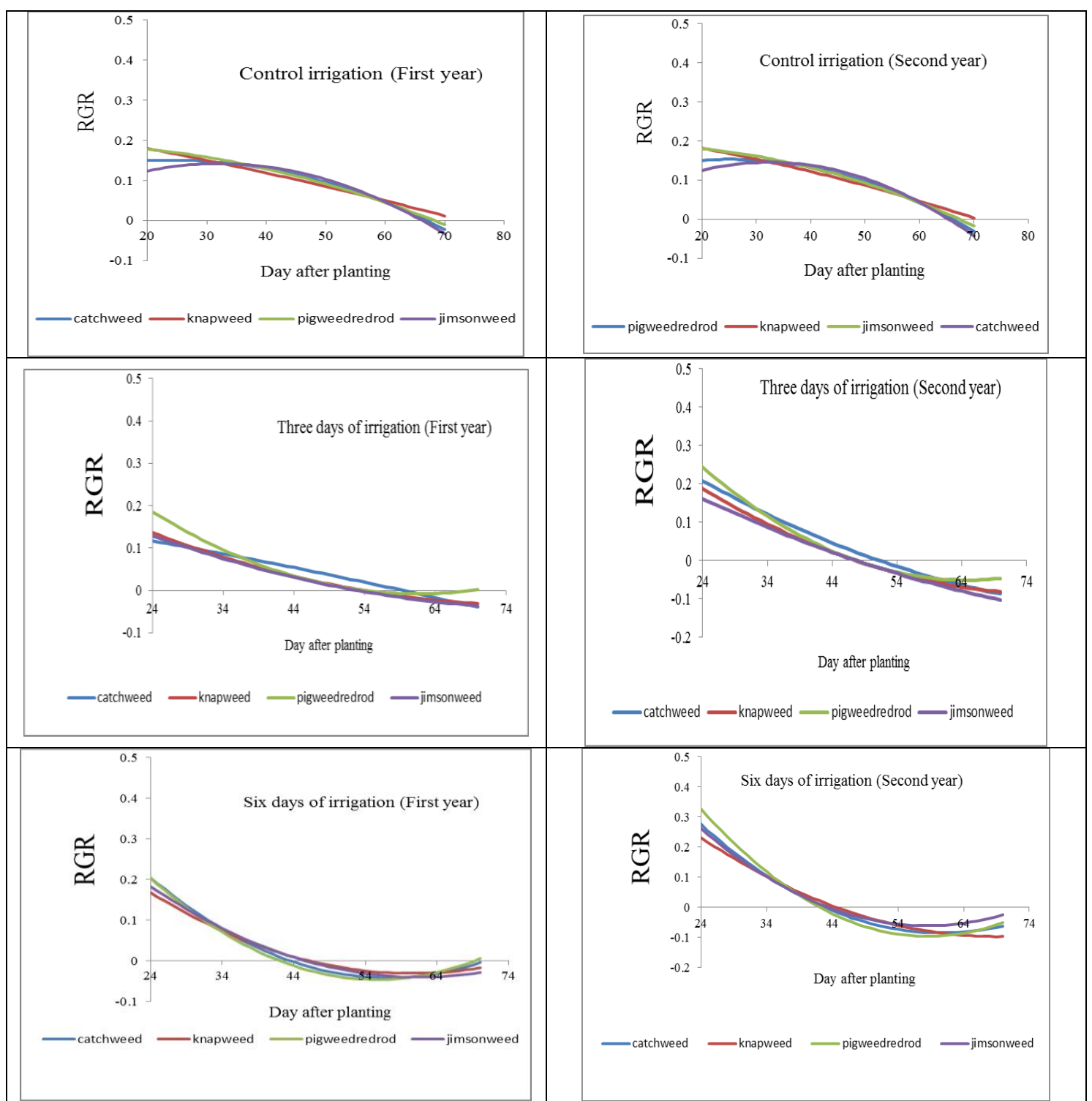

Figure 4. The effect of irrigation period on relative growth rate of weeds 


\section{Net assimilation rate (NAR)}

NAR starts the descent trend for all periods of irrigation, however, the slope falling of NAR was slower in control than other both irrigation periods (Fig. 5). Given that in normal mode, Nar decreases due to shading leaves, but in treatments under stress, even though, photosynthesis capacity is reduced due to the closure of stomata as a mechanism to combat water losses, however, due to the shortage of leaves numbers and lower leaf area, little shading is observed in less irrigated treatments. This results are controversial with the results obtained for LAI. The photosynthesis restriction under the influence of irrigation shortages has a greater effect on the falling of the NAR, than the shading of leaves, and that is the cause of an intensive slope falling of the NAR in long irrigation periods. Wise et al. (2013) stated that drought stress, which causing reduces in the leaf water potential to $-15 \mathrm{bar}$, reduces pure photosynthesis by up to $50 \%$, and the reason for this is the lack of stomatal conductivity due to the closure of the stomata. They also stated that cyclic and noncyclic photophosphorylation and electron transfer decrease under drought stress where the leaf water potential reaches between -10 to -11 atmospheres. However, water shortages affect enzymes of the dark reaction of photosynthesis. With the results, it can be said that in treatments under stress, with less shading leaves due to the lack of leaf area development, and photosynthesis limitation, single leaf photosynthesis is reduced and the effect of this factor is greater than that is of the shading leaves.

$$
\begin{gathered}
\text { NAR }=\text { CGR/LAI } \\
\text { NAR }=(b 1+2 c 1+3 d 1 t 2) e^{(a 1-a 2)+(b 1-b 2) t+(c 1-c 2) t 2+(d 1-d 2) t 3}
\end{gathered}
$$

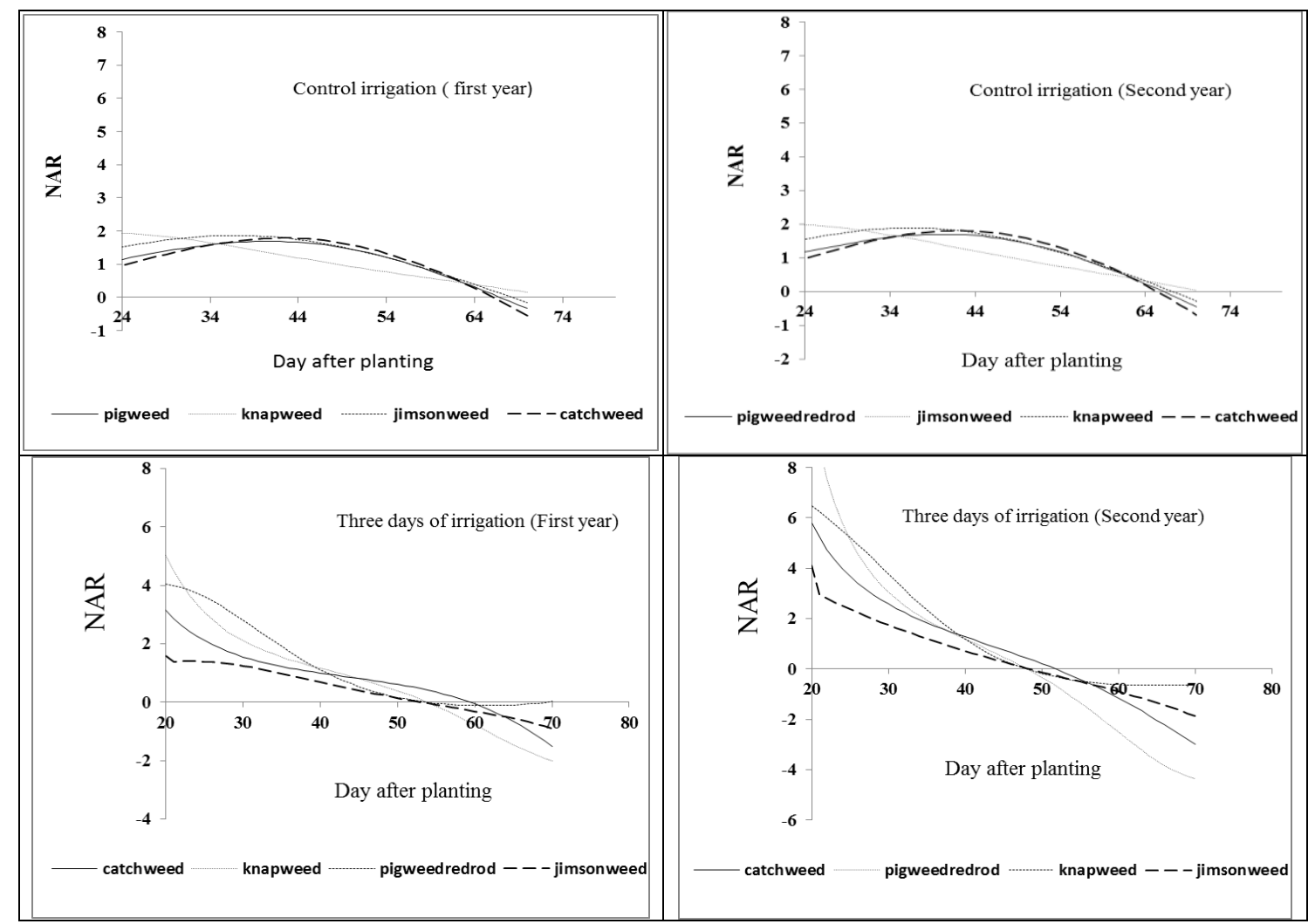




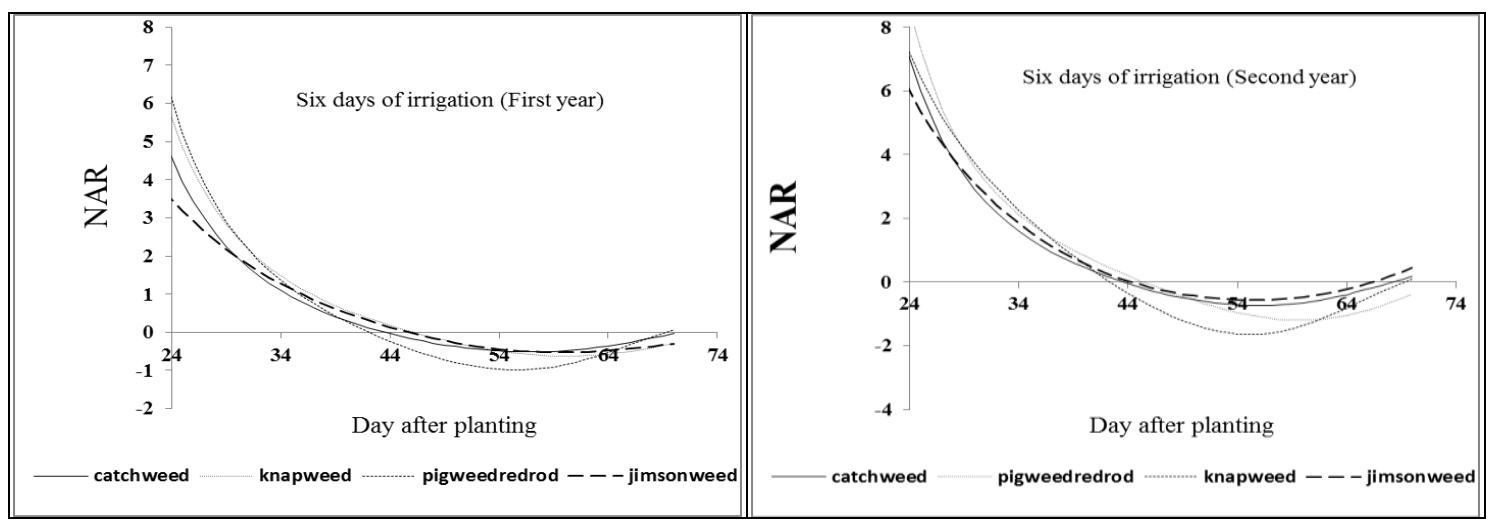

Figure 5. The effect of irrigation period on net assimilation rate of weeds

\section{Related traits to root and plant height}

ANOVA analysis was shown in Table 2. According to Table 3 in all sampling, in both years, Jimsonweed in control irrigation, and followed that, Red root pigweed has the highest height. Russian knapweed was the shortest plant among the species. By applying drought stress and increasing irrigation periods, the height of all weeds decreased, but the decrease in Jimsonweed height was higher than the Red root pigweed. This act can be attributed to the photosynthetic system of both plants. In conditions of water shortage and drought stress, C3 weeds has less competitive power than C4 weeds. Regarding the rate of weed height increase under normal conditions, Jimsonweed is stronger than other weeds and the optimum time to control it may be short. But, in drought stress conditions, the height of the Red root pigweed is higher and the control of the Red root pigweed is in the priority. Also, in the case of root weighing traits, in all weeds, with increasing irrigation period, root dry weight decreased. Nevertheless, the root length showed an increasing trend. During drought stress, soil layers are depleted from moisture, the root system penetrates into the depths of the soil (Klepper, 1990), and root density under stress conditions is much higher than in non-stress conditions. When exposed to drought stress, the plant allocates more dry matter to the root system to increase the absorbing ability of the roots, as a result, changes in the morphological characteristics of the roots are created, such as increasing the length of the roots per unit of weight (Aerts and Chapin, 2008).

Table 2. Analysis of variance of studied traits in different irrigation periods

\begin{tabular}{c|c|c|c|c}
\hline \multirow{2}{*}{} & \multirow{2}{*}{ d.f } & \multicolumn{3}{|c}{ Mean squares } \\
\cline { 3 - 5 } & & Root dry weight & Root length & Height \\
\hline Year (A) & 1 & $0.007^{\mathrm{ns}}$ & $0.04^{\mathrm{ns}}$ & $0.022^{\mathrm{ns}}$ \\
Error a & 6 & $0.03^{\mathrm{ns}}$ & $0.10^{\mathrm{ns}}$ & $0.248^{\mathrm{ns}}$ \\
Weed spices (B) & 3 & $34.52^{* *}$ & $22.51^{* *}$ & $5.478^{* *}$ \\
Irrigation (C) & 2 & $8.63^{* *}$ & $5.37^{* *}$ & $23.623^{* *}$ \\
$\mathrm{~A} \times \mathrm{B}$ & 3 & $0.0008^{\mathrm{ns}}$ & $0.07^{\mathrm{ns}}$ & $0.013^{\mathrm{ns}}$ \\
$\mathrm{A} \times \mathrm{C}$ & 2 & $0.001^{\mathrm{ns}}$ & $0.05^{\mathrm{ns}}$ & $0.006^{\mathrm{ns}}$ \\
$\mathrm{B} \times \mathrm{C}$ & 6 & $1.75^{* *}$ & $1.02^{* *}$ & $0.966^{* *}$ \\
$\mathrm{~A} \times \mathrm{B} \times \mathrm{C}$ & 6 & $0.02^{\mathrm{ns}}$ & $0.04^{\mathrm{ns}}$ & $0.025^{\mathrm{ns}}$ \\
Error B & 66 & 0.04 & 0.086 & 0.07 \\
$\% \mathrm{CV}$ & & 11.15 & 6.92 & 5.89 \\
\hline
\end{tabular}

$\mathrm{ns}, * * *$ Not significant $(\mathrm{P}>0.05)$, significant at $\mathrm{P}<0.05$, and $\mathrm{P}<0.01$ respectively 
Table 3. Comparison of the mean of studied traits in different irrigation periods

\begin{tabular}{c|c|c|c|c}
\hline ab & Irrigation & Root dry weight $(\mathbf{g}$ plant & $\mathbf{1})$ & Root length $(\mathbf{c m})^{\text {Height }(\mathbf{c m})}$ \\
\hline \multirow{4}{*}{ Amaranthus retroflexus } & Control & $23.35 \mathrm{a}$ & $7.50 \mathrm{f}$ & $31.55 \mathrm{~b}$ \\
& 3 day & $12.18 \mathrm{~b}$ & $9.21 \mathrm{ef}$ & $27.65 \mathrm{c}$ \\
& 6 day & $5.98 \mathrm{c}$ & $10.28 \mathrm{e}$ & $16.35 \mathrm{f}$ \\
\hline \multirow{3}{*}{ Datura stramonium } & Control & $4.95 \mathrm{c}$ & $24.88 \mathrm{~b}$ & $41.32 \mathrm{a}$ \\
& 3 day & $2.06 \mathrm{def}$ & $19.77 \mathrm{c}$ & $24.90 \mathrm{~d}$ \\
& 6 day & $1.90 \mathrm{efg}$ & $33.07 \mathrm{a}$ & $14.74 \mathrm{f}$ \\
\hline \multirow{3}{*}{ Setaria verticilata } & Control & $0.90 \mathrm{fgh}$ & $17.89 \mathrm{c}$ & $31.28 \mathrm{~b}$ \\
& 3 day & $0.53 \mathrm{gh}$ & $23.53 \mathrm{~b}$ & $20.87 \mathrm{e}$ \\
& 6 day & $0.32 \mathrm{~h}$ & $32.76 \mathrm{a}$ & $15.76 \mathrm{f}$ \\
\hline \multirow{3}{*}{ Acroptilon repens } & Control & $3.43 \mathrm{~d}$ & $13.52 \mathrm{~d}$ & $21.18 \mathrm{e}$ \\
& 3 day & $2.81 \mathrm{de}$ & $17.33 \mathrm{c}$ & $15.178 \mathrm{f}$ \\
& 6 day & $1.59 \mathrm{efgh}$ & $17.67 \mathrm{c}$ & $11.91 \mathrm{~g}$ \\
\hline
\end{tabular}

\section{Conclusion}

The results showed that all indices decreased by increasing irrigation period. Red root pigweed showed more tolerance to long irrigation period than others. Thus in dried condition red root pigweed can be weed dominant. Unlike, Jimsonweed showed a better growth in control.

\section{REFERENCES}

[1] Aerts, R., Chapin, F. S. (2008): The mineral nutrition of wild plants revisited: reevaluation of processes and patterns. - Advances in Ecological Research 62: 26-34.

[2] Beech, D. F., Norman, M. J. T (2002): The effect of time of planting on y attributes of varieties of safflower. - Australian Journal of Basic Applied Sciences 3: 140-148.

[3] Benvenuti, S., Macchia, M., Mieles, S. (2001). Quantitative analysis of emergence of seedlings from buried weed seeds with increasing soil depth. - Weed Science 49: 528535.

[4] Chauhan, B. S. (2013): Growth response of itchgrass (Rottboellia cochinchinensis) to water stress. - Weed Science 61: 98-103.

[5] Chauhan, B. S., Johnson, D. E. (2010): Growth and reproduction of Jungle rice (Echinochloa colona) in response to water stress. - Weed Science 58: 132-135.

[6] Eslami, R., Tajbakhsh, M., Ghafari, A., Roustaei, M., Barnousi, I. (2012): Evaluation of drought tolerance in dry lands wheat genotypes under different moisture. - Electronic Journal of Crop Production 2: 129-143.

[7] Human, J. J., Tolit, J. D., Vezuidenhout, H. D. Bryun, L. P. (1990): The influence of photosynthesis and yield of sunflower. - Agric.Res.37:542-549.

[8] Karim Zadeh Asl, K. H., Mazaheri, D., Peyghambari, S. A. (2004): Effect of four irrigation periods on seed yield and physiologyical indexes of three sunflower cultivars. Desert (BIABAN) 9(2): 255-266.

[9] Klepper, B. (1990): Root Growth and Water Uptake. - In: Stewart, B. A., Nielsen, D. R. (eds.) Irrigation of Agricultural Crops. Agron. Monogr. 30. ASA, CSSA, and SSSA, Madison, WI, pp. 281-322.

[10] Kochaki, A., Sarmadni (1990): Plant Physiology. 2nd Ed. - Jahad University Press. Ferdosi Mashhad University.

[11] Monaco, T. J., Weller, S. C., Ashton, F. M. (2002): Weed Science: Principles and Practices. 4th Ed. - John Wiley and Sons, Inc., New York. 
[12] Peters, K., Breitsameter, L., Gerowitt, B. (2014): Impact of climate change on weeds in agriculture: a review. - Agron. Sustain. Dev. 34: 707-721.

[13] Russell, M. P., Wilhelm, W. W., Olsson, R. A., Power, J. F. (1984): Growth analysis based on degree day. - Crop Sci. 24: 28-32.

[14] Rawson, H. M., Turner, N. C. (1982): Recovery from water stress in five sunflower cultivars. Effect of the timing of water application on leaf area and seed production. Aus. Plant Physiol. 9: 437.

[15] Sadeghi, H., Bagestani, M. H., Akbari, G. A., Hejazi, A. (2009): Evaluation of soybean (Glycine Ma.) and some weed species growth indices under competition condition. Entomology and Phytopathology 71: 88-106.

[16] Webster, T. M., Grey, T. L. (2008): Growth and reproduction of Benghal dayflower (Commelina benghalensis) in response to drought stress. - Weed Science 56: 561-566.

[17] Wise, R. R., Fredrick, J. R., Alm, D. M., Kramer, D. M., Hesketh, J. D., Crofts, A. R., Ort, D. R. (2013): Investigation of photosynthesis induced leaf water deficits in field grown sunflower. - Uir. of III Ineis Cell Environ 913L: 923-931.

[18] Zimdahl, R. L. (2013): Fundamentals of Weed Science. 4th Ed. - Academic Press, San. Diego, USA. 